\title{
Coulisses
}

Revue de théâtre

10 | Printemps 1994

Varia

\section{De Corps à une co-production bilatérale}

De la Franche-Comté au Nord-Portugal

\section{(2) OpenEdition}

\section{Journals}

Édition électronique

URL : http://journals.openedition.org/coulisses/3095

DOI : 10.4000/coulisses.3095

ISSN : 2546-9460

\section{Éditeur}

Presses universitaires de Franche-Comté

Édition imprimée

Date de publication : 1 juin 1994

Pagination : 76

ISSN : 1150-594X

\section{Référence électronique}

"De Corps à une co-production bilatérale », Coulisses [En ligne], 10 | Printemps 1994, mis en ligne le 15 mars 2019, consulté le 26 octobre 2019. URL : http://journals.openedition.org/coulisses/3095 ; DOI : $10.4000 /$ coulisses.3095

Ce document a été généré automatiquement le 26 octobre 2019

Coulisses 


\title{
De Corps à une co-production bilatérale
}

\author{
De la Franche-Comté au Nord-Portugal
}

1 Depuis sa création le Théâtre Universitaire de Franche-Comté propose à ses adhérents un atelier approfondissement, ce qui veut dire retravailler la création de l'année précédente dans une autre optique, expérimenter d'autres méthodes puisque, généralement le groupe se retrouve avec la moitié de son effectif initial.

Après avoir approfondi les intentions et la réflexion, retravaillé la mise en scène en fonction du nombre et pour un dispositif frontal, il est possible de proposer le travail au jugement du public.

2 Ainsi, CORPS a été repris avec vingt-trois étudiants au lieu des quarante-trois de la création. Il a été donné en co-production avec l'ONG de Terre des Hommes, à la salle du Montjoye à Besançon les 19 et 20 février, puis invité au théâtre de Giromagny le 25 mars, participé aux $5^{\text {èmes }}$ Rencontres Théâtrales de l'Ecole Nationale des travaux publics de l'Etat. Il a été invité par les Théâtres Universitaires de Braga et de Porto pour mettre en place la phase de préparation d'une co-production.

3 Les déplacements souvent très éprouvants, donnent la possibilité aux étudiants de se confronter avec d'autres spectateurs, d'autres TU, de prendre intimement la mesure de ses limites et de ses aspirations. C'est aussi l'occasion de rencontrer les autres, particulièrement les étrangers, et c'est une expérience exceptionnelle aussi bien artistique que personnelle pour les étudiants qui participent à l'aventure.

4 La tournée au Portugal avait ceci de spécial qu'elle représentait la première étape d'un projet de co-production entre les TU du Nord-Portugal et de Franche-Comté. L'objectif général était donc une prise de contact entre le T.U.F.C et les trois groupes portugais par les représentations de CORPS à Braga puis à Porto, l'organisation des manifestations de juin 1994 à Besançon et de la co-production en 1995 


\section{Espagne}

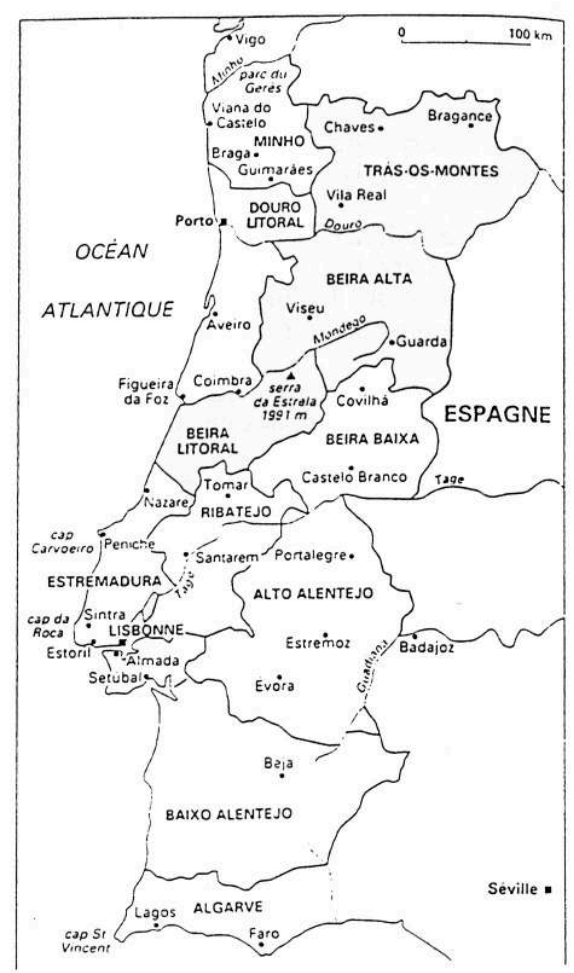

